\title{
Percutaneous Closure of Patent Ductus Arteriosus in Situs Inversus Dextrocardia with Interrupted Inferior Vena Cava through Internal Jugular Vein Approach
}

\author{
Ashish Tiwari*, Vivek Kumar, Suresh PV, Satheesh S, Sarraf R and Prakash R \\ Department of Cardiology Narayana Hrudayalaya Bengaluru, India
}

Submission: January 28, 2019; Published: March 11, 2019

*Corresponding author: Ashish Tiwari, Department of Cardiology, LARI Cardiology Centre King George's Medical University, Shahmina Road, Lucknow, INDIA, 226003

\begin{abstract}
Percutaneous closure of Patent Ductus Arteriosus (PDA) through femoral vein approach is an established standard practice. Though device closure of PDA in interrupted Inferior Vena Cava (IVC) with Azygous continuation is technically challenging, it had been reported both through femoral vein and internal jugular vein approach [1-4]. We report a case of transcatheter closure of moderate PDA through internal jugular vein approach, using Amplatzer Duct Occluder (ADO I) in a five-year-old girl with situs inversus Dextrocardia and interrupted IVC with Azygous continuation. It was challenging because of the mirror image anatomy and the complexity of the curve which the delivery sheath had to take. To the best of our knowledge PDA device closure through internal jugular vein approach in such a complex anatomy had never been reported.

Keywords: PDA; Interruption of inferior vena cava; Internal jugular vein approach; Amplatzer duct occluder I

Keywords: PDA: Patent Ductus Arteriosus; IVC: Inferior Vena Cava; ADO I: Amplatzer Duct Occluder; LV: Left Ventricular; ECG: Electrocardiogram; SVC: Superior Vena Cava; PA: Pulmonary Artery; RAO: Right Axial Oblique; LAO: Left Axial Oblique; IVC: Inferior Vena Cava
\end{abstract}

\section{Introduction}

Interrupted IVC is a rare anomaly with an incidence of 1 in 5000 cases [5]. It has a strong association with polysplenia (86\%). As a rule, it is generally associated with situs abnormalities and complex congenital heart defects. Although PDA device closure in an interrupted IVC is technically difficult, procedure done through internal jugular, femoral vein and retrograde trans arterial approach had been reported [1-3]. We describe a novel case in which we did PDA device closure in a five-year-old girl with situs inversus Dextrocardia interrupted IVC with Azygous continuation through trans jugular approach.

\section{Case Report}

Five-year-old girl weighing $11 \mathrm{~kg}$ presented with a history of incidental murmur detected during an upper respiratory tract infection episode. On examination she had failure to thrive, Dextrocardia, Left Ventricular (LV) apex, normal heart sounds and a grade $4 / 6$ continuous murmur in the right infraclavicular area. Her 12 lead Electrocardiogram (ECG) revealed inverted p wave in lead 1 and sinus rhythm with evidence of Left Ventricular enlargement. Chest X-ray showed Dextrocardia, cardiothoracic ratio of 0.65 and plethoric lung fields. Transthoracic 2D echocardiography confirmed a moderate PDA measuring 4 $\mathrm{mm}$ at its narrowest point with evidence of LA and LV volume overload. Doppler revealed continuous flow across the PDA with peak systolic gradient of $91 \mathrm{mmHg}$ and end diastolic gradient of $24 \mathrm{mmHg}$.She had interrupted IVC on Echocardiography. Her ultrasound abdomen revealed mirror image displacement of the viscera with a single spleen on the right side. It was decided to take her for percutaneous closure of PDA after delineating the anatomy.

\section{Procedure}

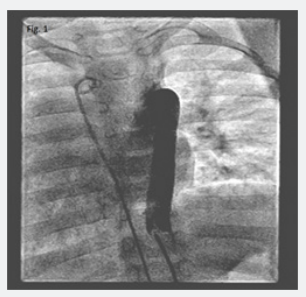

Figure 1: Contrast injection in the inferior vena cava showing azygous continuation from an interrupted inferior vena cava. 
After obtaining parental consent patient was taken for device closure. Right femoral vein, artery and left internal jugular vein were cannulated with $5 \mathrm{Fr}, 4 \mathrm{Fr}$ and $5 \mathrm{Fr}$ sheaths respectively. Right heart catheterization showed IVC interruption with azygous continuation into left Superior Vena Cava (SVC) (Figure 1). Hemodynamic data revealed systemic arterial pressure of 130/50/80 mmHg and Pulmonary Artery (PA) pressure of 60/30/40 mmHg (moderate pulmonary hypertension). Descending aortogram was done in Right Axial Oblique (RAO) 90 and Left Axial Oblique (LAO) 30. It revealed a conical PDA filling the pulmonary artery (Figure 2A \& 2B) with minimal diameter of $4.3 \mathrm{~mm}$ at the Pulmonary Artery (PA) end and $11.5 \mathrm{~mm}$ at the aortic ampulla. $5 \mathrm{~F}$ multipurpose catheter was crossed in to the descending aorta over straight tip 0.032" Terumo wire (Terumo, Tokyo Japan). Terumo wire was then exchanged with extra stiff Amplatzer wire. 7F unbraided Cook sheath was then passed over the Amplatzer wire in to the descending Aorta (Figure 3). While negotiating cook sheath in to the PDA, maneuvering was difficult as compared to femoral approach. 0806 Amplatzer duct Occluder I (ADO I) was loaded on a 6F loading sheath and the device was deployed in LAO 30 view (Figure 4). Check angiogram post deployment showed device in place with no residual leak.

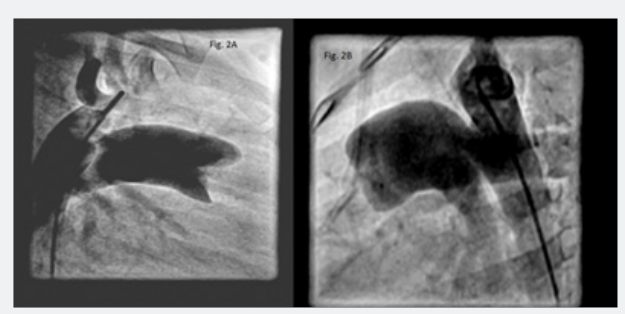

Figure 2A \& 2B: Descending aortogram in LAO 30 \& RAO 90 demonstrating Krichenko type A PDA.

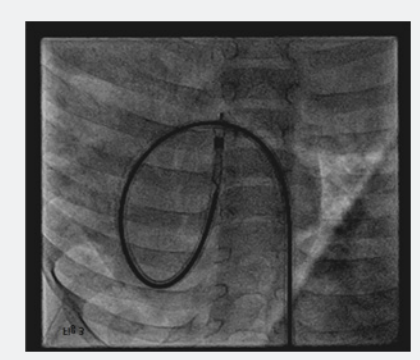

Figure 3: Cook sheath with delivery system (Left Internal Jugular Vein to Descending aorta).

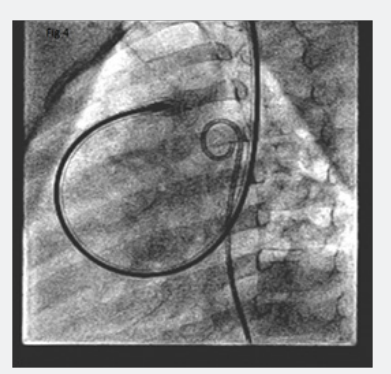

Figure 4: Device delivery in Frontal view.

\section{Discussion}

Percutaneous closure of Patent Ductus Arteriosus (PDA) through femoral vein approach is an established standard practice. Closure of a PDA in a patient with Inferior Vena Cava (IVC) interruption can be both technically demanding and challenging. Technical problems have been encountered often because of the failure of advancing the sheath and kinking at the acute angle of azygous and superior vena cava junction and the right ventricular outflow tract toward the pulmonary artery [1]. So femoral vein approach is extremely difficult, and many a times proves as a futile exercise. Although PDA device closure in an interrupted IVC is technically difficult, procedure done through internal jugular, femoral vein and retrograde trans arterial approach had been reported [1-3]. In our case we preferred LIJV approach for a 5-year-old girl referred to us with diagnosis of Moderate PDA, Dextrocardia and Interrupted IVC. PDA was profiled angiographically and 0806 size Amplatzer duct Occluder I deployed for $4.3 \mathrm{~mm}$ PDA. Procedure went uneventfully and there was no post procedure complication. Patient was discharged successfully and on regular follow-up with us.

Previously Sivakumar and Francis reported having closed a duct through retrograde approach from the aorta with a reversed device position, that is, the aortic disc facing the pulmonary artery and the tubular end facing the aorta [2]. Koh and co-workers used the transarterial approach but with an ADO II device, which has discs on both sides [6]. Our technique was similar to Akhtar and co-workers reported closure of a patent arterial duct through a right internal jugular vein approach in a patient with interrupted inferior caval vein and blood flow directed to a hepatic venous plexus [1].

Though there are case reported of PDA closure in anomalous inferior vena cava, this case was unique in the presence of Dextrocardia, mirror image anatomy and interrupted IVC. It was challenging because of the mirror image anatomy and the complexity of the curve which the delivery sheath had to take. We conclude that in cases of PDA with interrupted IVC and complex anatomy, IJV approach can be successfully used. To the best of our knowledge PDA device closure through internal jugular vein approach in such a complex anatomy had never been reported.

\section{Declaration of Conflicting Interests}

The author(s) declared no potential conflicts of interest with respect to the research, authorship, and/or publication of this article.

\section{References}

1. Akhtar S, Samad SM, Atiq M (2010) Transcatheter closure of a patent ductus arteriosus in a patient with an anomalous inferior vena cava. Pediatr Cardiol 31(7): 1093-1095.

2. Sivakumar K, Francis E (2007) Anomalous inferior vena cava drainage to portal vein offers a challenge to transcatheter ductus arteriosus closure. Pediatr Cardiol 28(5): 416-417.

3. Al-Hamash S (2006) Transcatheter closure of patent ductus arteriosus 
and interruption of inferior vena cava with azygous continuation using an amplatzer duct occluder. Pediatr Cardiol 27(5): 618-620.

4. Patel NH, Madan TH, Panchal AM, Thakkar BM (2009) Percutaneous closure of patent ductus arteriosus via internal jugular vein in patient with interrupted inferior vena cava. Ann Pediatr Cardiol 2(2): 162-164.

5. Bronshtein M, Khatib N, Blumenfeld Z (2010) Prenatal diagnosis and outcome of isolated inferior vena cava. Am J Obstet Gynecol 202(4): 398.e1-4.
6. Koh GT, Mokthar SA, Hamzah A, Kaur J (2009) Transcatheter closure of patent ductus arteriosus and interruption of inferior vena cava with azygos continuation using an Amplatzer duct occluder II. Ann Pediatr Cardiol 2(2): 159-161.
This work is licensed under Creative

Commons Attribution 4.0 License

DOI: 10.19080/JOCCT.2019.13.555859

\section{Your next submission with Juniper Publishers} will reach you the below assets

- Quality Editorial service

- Swift Peer Review

- Reprints availability

- E-prints Service

- Manuscript Podcast for convenient understanding

- Global attainment for your research

- Manuscript accessibility in different formats

( Pdf, E-pub, Full Text, Audio)

- Unceasing customer service

Track the below URL for one-step submission https://juniperpublishers.com/online-submission.php 